\title{
Are Native and Nonindigenous Seaweeds Overgrowing Florida's East Coast Reefs?
}

by Charles Jacoby ${ }^{1}$, Brian Lapointe ${ }^{2}$, and LeRoy Creswell ${ }^{3}$

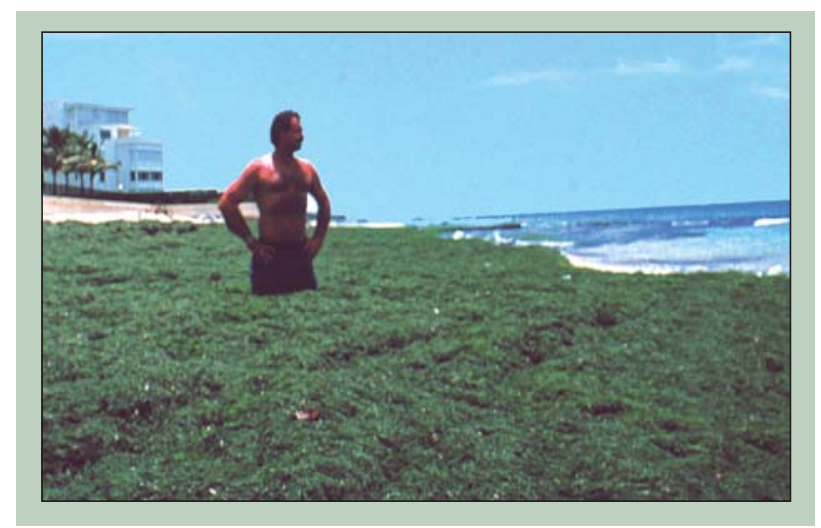

Codium isthmocladum (Brian Lapointe)

\section{Seaweed? What seaweed?}

Brian Lapointe and his colleagues from the Harbor Branch Oceanographic Institution (HBOI) first became concerned about excessive growth of green macroalgae or seaweeds around 1990. They spotted drifting mats of the green seaweed Codium isthmnocladum on reefs in 24-40 meters of water (78-131 feet) off southern Palm Beach and northern Broward counties. These mats were up to 2 meters thick ( 6.5 feet), and they covered other plants, corals, sponges and other animals. When the algae washed ashore, it made beaches less attractive to residents and tourists.

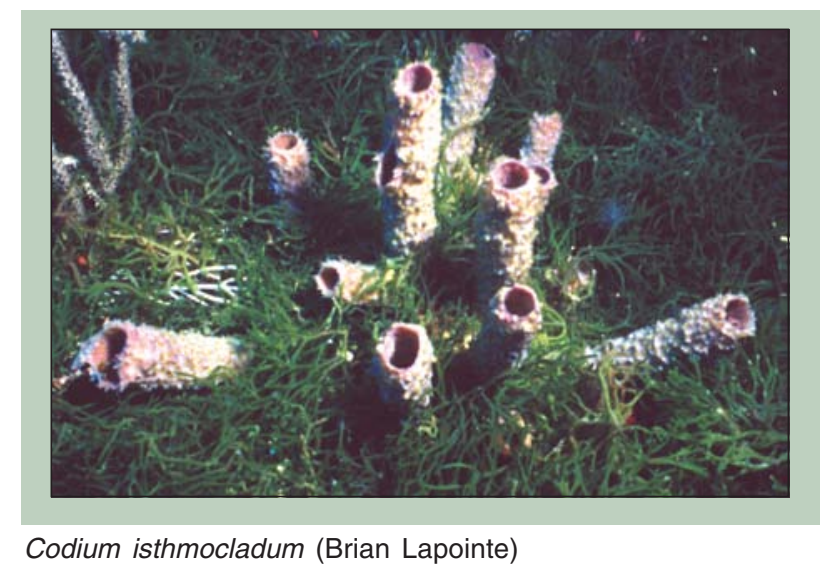

By 1995, C. isthmocladum had spread onto reefs in northern Palm Beach County, and some of the plants had attached to the bottom. Although extensive growth of C. isthmocladum was of concern, this alga had been seen in Florida's coastal waters, so this was not a case of an invasion by a nonindigenous or non-native seaweed.

The discovery of $C$. isthmocladum was followed by the discovery of large beds of another green alga, Caulerpa verticillata. In the fall of 1997, HBOI scientists discovered C. verticillata growing on reefs off Singer Island just north of the Princess Anne, an artificial reef that was sunk by Palm Beach County in 1992.
C. verticillata is a small plant that typically grows in nutrient-rich mangrove habitats and near seabird rookeries where guano adds nutrients to the water. Although found in such habitats in Florida, C. verticillata had not been observed on Palm Beach County's reefs. Surveys during following years documented its spread northward to Jupiter Inlet. Large areas of reef became covered by this small plant, which can inhibit settlement and growth of coral and other plants and animals.

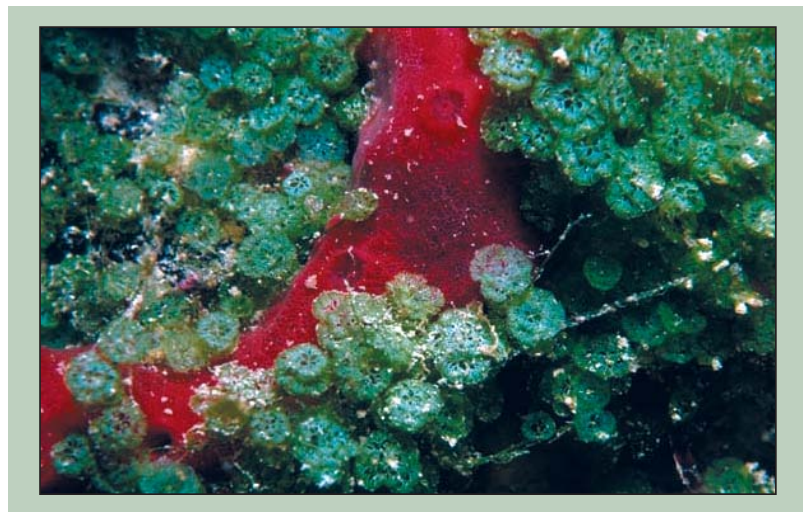

Caulerpa verticillata (John Reed)

Another larger, native, green alga, Caulerpa racemosa, also became increasingly conspicuous and abundant during the late 1990s. Unlike Codium, Caulerpa does not rely entirely on nutrients in the water column for growth. It can draw nutrients from sediments through its root-like stolons and rhizoids.

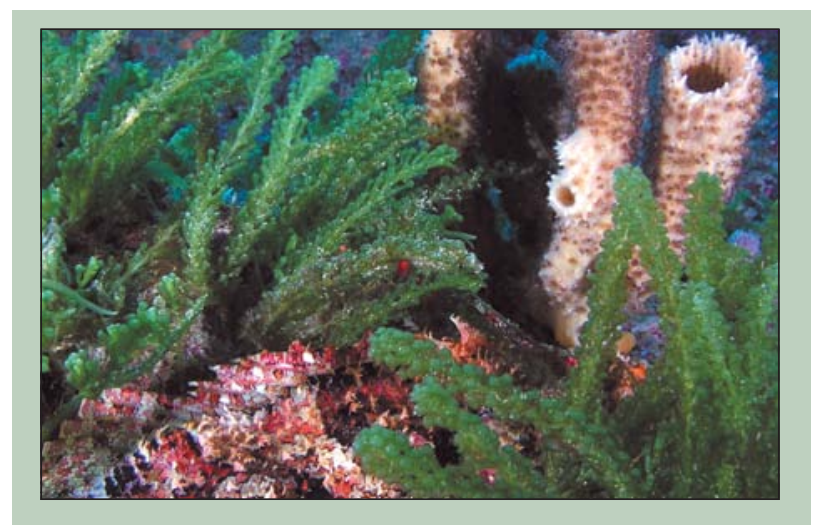

Caulerpa racemosa (Lazaro Ruda)

Department of Fisheries and Aquatic Sciences, University of Florida, Box 110600, Gainesville, FL 32611-0600; phone (352) 392-96117, ext. 272; cajacoby@ufl.edu

2 Division of Marine Science, Harbor Branch Oceanographic Institution, 5600 US 1 North, Ft. Pierce, FL 34946; phone (772) 465-2400, ext. 276; lapointe@ hboi.edu

3 Florida Sea Grant Marine Extension Service, 8400 Picos Road, Suite 101, Ft. Pierce, FL 34945-3045; phone (772) 462-1660; Lcreswell@ifas.ufl.edu 
In May 2001, HBOI scientists funded by Florida's Harmful Algal Bloom Task Force were surveying algae throughout Palm Beach and northern Broward counties. On the first dive off Singer Island, they discovered extensive blooms of the green alga Caulerpa brachypus at a depth of 43 meters (141 feet). C. brachypus is not native to Florida's east coast. It is a native of the Pacific Ocean rather than the Atlantic.

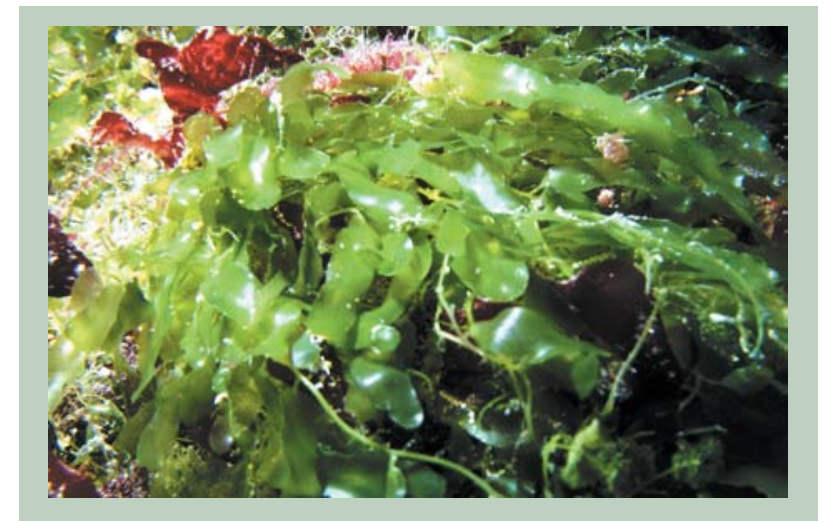

Caulerpa brachypus (Geoff Oldfather)

Subsequent surveys showed that $C$. brachypus was widespread in waters 20-43 meters deep (65-141 feet) off northern Palm Beach County. The algae had overgrown or displaced other macroalgae, sponges and corals. C. brachypus has since been reported off Pepper Park in Fort Pierce, and in early March 2003, it was found in the Indian River Lagoon around the Jensen Beach causeway and Jupiter Inlet.

C. brachypus will probably continue spreading north and south from Palm Beach County. At this time, the total area covered remains unknown. This nonindigenous species may have become invasive because it may be causing harm. Dive operators and fisherman have reported that $C$. brachypus is so thick off Palm Beach County that it is forcing fish and lobster away from reefs.

There is good reason to be concerned about the spread of $C$. brachypus in Florida's coastal waters. A related green alga, Caulerpa taxifolia, spread from a small patch (1 square meter or 10.8 square feet) to cover almost everything for 131 square kilometers (50.6 square miles) along the Mediterranean coast. This same species has been found at sites in California where authorities are spending millions of dollars to eradicate it before it spreads. (For more information, please see the related fact sheet Can we stop "killer algae" from invading Florida? [SGEF-155] by Linda Walters and Charles Jacoby.)

\section{What problems arise from blooms of macroalgae?}

Macroalgal blooms can produce undesirable ecological and economic consequences. They can be especially damaging to coral reefs where macroalgae overgrow and replace these animals. The resulting reduction in biological diversity lowers habitat quality and aesthetics, which can cause decreases in fisheries production and tourism. Macroalgal blooms also overgrow seagrasses resulting in similar effects.

In addition, when macroalgae respire or die and decompose, they use oxygen. Large amounts of macroalgae can use enough oxygen to cause hypoxia (low oxygen levels in the water) or anoxia (essentially no oxygen in the water). If oxygen levels fall low enough for long enough, other plants and animals will die.

If blooms of macroalgae cause ecological and economic damage, they can be classed as harmful algal blooms. Macroalgal blooms can be as destructive as "red tides" that produce toxic compounds capable of killing fish or marine mammals.

\section{What does this have to do with me?}

We fit into this picture by being potential contributors to the cause of macroalgal blooms. Blooms of macroalgae can be symptomatic of increased nutrients in coastal waters. Increasing nutrient loads occur near coastlines around the world, especially in areas with rapid population growth or extensive agricultural or industrial activities. Sewage, fertilizers in runoff, and atmospheric deposition of nitrogen from car exhaust or industrial emissions all contribute nitrogen or phosphorus that can fuel macroalgal blooms. Natural inputs of nutrients can also fuel macroalgal blooms, but the frequency and extent of blooms appears to be increasing as populations increase along the coast of Florida. In contrast, natural inputs of nutrients by upwelling or other events do not appear to be increasing. In addition, surveys funded by Sea Grant and conducted by LaPointe and his colleagues indicate that many green algae seem to use nitrogen from sewage rather than nitrogen from natural inputs.

We can all work to lower the amount of nutrients that find their way into Florida's coastal waters. Maintaining septic systems and using fertilizer wisely are two key ways to help lower nutrient loads. Working with authorities to reduce nutrient loads from sewage treatment plants represents another way to lower nutrient inputs and avoid fueling macroalgal blooms.
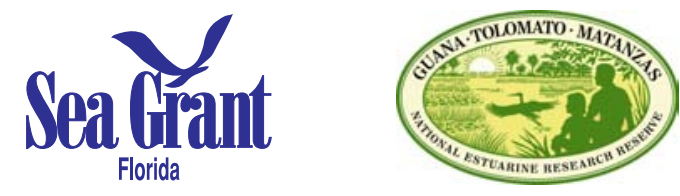

UNIVERSITY OF FLORIDA

IFAS EXTENSION

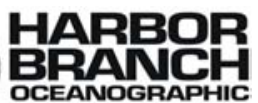

